\title{
Soil Categorization Using Vs30 Mapping, to Evaluate Probable Structural Effects of an Earthquake on a Proposed Construction Site
}

\author{
Collins C. Chiemeke \\ Physics Department, Federal University Otuoke, Bayelsa State, Nigeria
}

\begin{abstract}
This research work was carried out with the aim of using average shear wave velocity of the top $30 \mathrm{~m}$ (Vs30), technique to categorize the soil, and ascertain the probable resistance or damage that the structure placed on it could suffer in the event of damaging earthquake. In a bid to achieve this, downhole seismic survey was carried out in eight boreholes within the same site, all drilled to 30 m depth. The field procedure used involves lowering of hydrophone into the borehole at an interval of $1 \mathrm{~m}$, and striking a sledge hammer on base plate at a fixed distance of $3 \mathrm{~m}$ to generate seismic signals. The data were processed and the results revealed that, the distribution of average shear wave velocity of the top $30 \mathrm{~m}$ (Vs30) is not always even within a given site; instead, you have regions with low Vs30, and regions with high Vs30. The results indicated the presence of overburden layer (lose sand layer) within the site under investigation, and also revealed that in most instances, regions with low Vs30 match up with regions with thick overburden, and regions with high Vs30 correspond with regions with thin overburden cover. The research has shown that, in the event of damaging earthquake the regions with low Vs30 and relatively thick overburden cover will experience more of the amplification of the low frequency seismic waves, and consequently more damage to structures erected within that vicinity. Hence, regions with low Vs30 and thick overburden cover will require engineering remediation to improve its resistance to shaking and load bearing capacity, and to reduce the amplification of low frequency seismic waves in the event of ground shaking induced by an earthquake.
\end{abstract}

Keywords: Vs30, Earthquake, Construction Site, Downhole, Seismic, Shear wave.

\section{INTRODUCTION}

This investigation was carried out with the sole aim of making use of Vs30 technique to categorize the soil within a given site, and to ascertain the probable effect of a damaging Earthquake on any structure erected at the site. Therefore a high resolution downhole seismic method that has the ability to accurately determine the shear wave velocities, and delineate each layer was used in this research work. Previous research done in these area have shown that; "In post 1994 U.S. seismic codes a new soil categorization scheme was introduced, which uses Vs30 as the main categorization parameter" [4]. "[1] stated that "After conducting a detailed study in the Dinar Region, it is observed that the poor soil condition effects are clear on the damage distribution". "The high resolution downhole seismic method was able to identify two lithological units of sand layer base on their seismic velocities values" [2]. The instruments used for the data acquisition include ABEM Terraloc Digital Seismograph, Hydrophone, Sledge Hammer, Base plate, Reels of Cables and sealed 12 V Battery.

\section{GEOLOGY OF THE AREA}

The Formation of the present Niger Delta started during Early Paleocene as a result of the built up of fine grained sediments eroded and transported to the area by the River Niger and its tributaries. The regional geology of the Niger Delta consists of three lithostratigraphic units; Akata, Agbada and Benin Formations, overlain by various types of Quaternary Deposits [6], [7], [3]. These Quaternary Sediments, according to [5] are largely alluvial and hydromorphic soils and lacustrine sediments of Pleistocene age.

\section{LOCATION OF STUDY AREA}

The study area is located within the oil rich Niger Delta, of Delta State Nigeria. With an average elevation of $9 \mathrm{~m}$ above mean sea level. The Imagery Map of the survey area displaying the borehole point is shown in figure 1 .

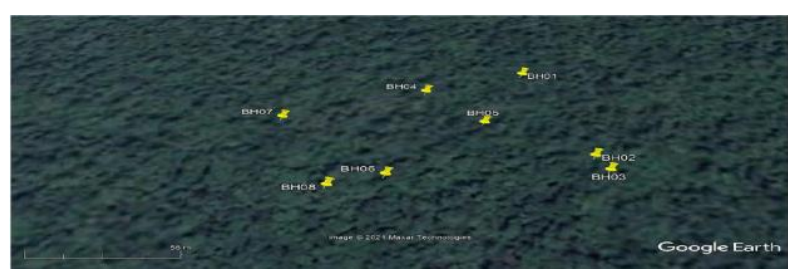

Figure 1: Imagery Map of the Survey area, displaying the various borehole locations 


\section{DATA ACQUISITION}

The data acquisition for the downhole seismic test started with measurement of the depth of the drilled borehole, after which an offset distance of $3 \mathrm{~m}$ from the borehole was measured. The digital Seismograph was set up along with its accessories. The hydrophone was connected to the first takeout of the reel of cable connect to the Seismograph. The Hydrophone was first placed at the surface and the energy source was initiated by striking a sledge hammer on a base plate placed at an offset distance of $3 \mathrm{~m}$ to generate a seismic signal, which was detected by the hydrophone, and recorded by the Seismograph.

The hydrophone was then lowered into the hole at a depth of $1 \mathrm{~m}$, and the energy source was used to generate seismic wave as before. The process was repeated, with each time the hydrophone being lowered at $1 \mathrm{~m}$ interval, until the highest depth of $30 \mathrm{~m}$ was sampled. The generated seismograms were recorded for onward processing at the workstation.

\section{DATA PROCESSING}

The downhole seismic data was processed by importing it into a dedicated software used for the data processing. The bandpass frequency filter was applied to filter out the surface wave signal. The gain filter was applied to remove the effect of geometrical spreading. The Primary and shear waves were identified, and their first arrival was picked. The picked arrival times were used along with other parameters to calculate the intervening primary and shear wave velocity in each layer, as shown in Table 1 and 2.

Table 1: Primary and shear wave velocities distribution pattern with depth for boreholes 1 to 4

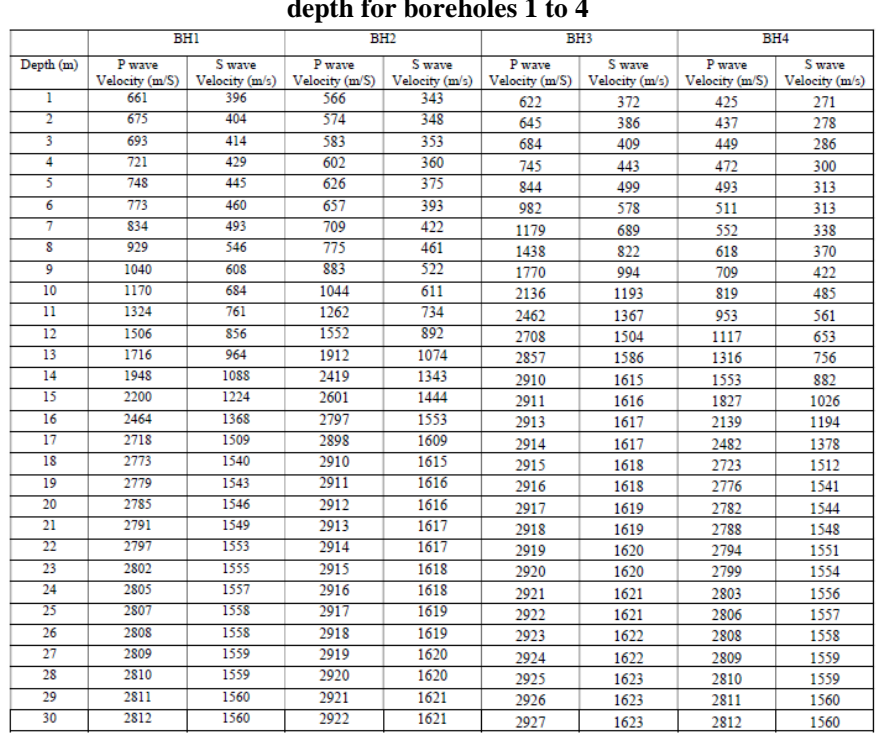

Table 2: Primary and shear wave velocities distribution pattern with depth for boreholes 5 to 8

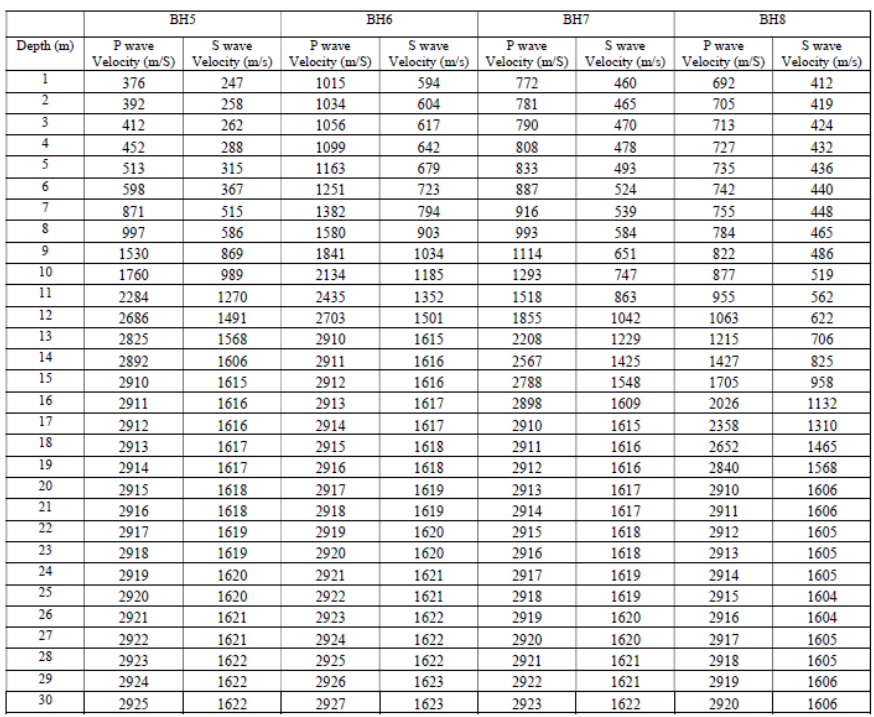

\section{RESULTS AND DISCUSSION}

The results of the downhole seismic test to determine the Primary and shear wave velocities distribution pattern with depth is shown in table 1 and 2. The primary and shear waves velocities registered a general increase of seismic wave velocity with depth. The range of seismic velocities within the site is between $376 \mathrm{~m} / \mathrm{s}$ to $2927 \mathrm{~m} / \mathrm{s}$ for primary wave and 247 $\mathrm{m} / \mathrm{s}$ to $1623 \mathrm{~m} / \mathrm{s}$ for shear wave.

The results of the average shear wave velocity of the top 30 $\mathrm{m}(\mathrm{Vs} 30)$ distribution are shown in table 3, figure 2 and 3 . The figures depict regions of low Vs30 and regions of high Vs30 distribution. Borehole 4 is located in the region with the least Vs30, while borehole 6 is located in the region with the highest Vs30, and the general picture of the investigated site showed that, region with high Vs30 is sandwiched by region with low Vs30. To effectively evaluate the effect of damaging earthquake on the site under investigation the overburden thickness within the site were determined. The range of primary wave velocities of between $376 \mathrm{~m} / \mathrm{s}$ to $1099 \mathrm{~m} / \mathrm{s}$ and $247 \mathrm{~m} / \mathrm{s}$ to $642 \mathrm{~m} / \mathrm{s}$ for shear waves indicate the occurrence of overburden (loose ground) cover, within the site under investigation, as shown in table 3.The determined thickness of the overburden cover is shown in figure 4 and 5. The thickness of the overburden showed a striking correlation with the average shear wave velocity of the top $30 \mathrm{~m}$ (Vs30). It is evident that apart from very few selected point, the region with high overburden thickness like borehole 4 has very low average shear wave velocity of the top $30 \mathrm{~m}$ (Vs30), while regions with very thin overburden cover like borehole 6 has high average shear wave velocity of the top $30 \mathrm{~m}$ (Vs30). 
ISSN (online): 2581-3048

It is apparent that structures placed within the region with low average shear wave velocity of the top $30 \mathrm{~m}$ (Vs30) and large thick overburden will be more affected by damaging earthquake than region with high average shear wave velocity of the top $30 \mathrm{~m}$ (Vs30) and small overburden thickness. Therefore, it gave an indication that regions with low average shear wave velocity of the top $30 \mathrm{~m}$ (Vs30) will see more amplification of the low frequency seismic waves from a damaging earthquake. To ascertain this further, the site coefficients at short and 1 second period was determined as shown in table 4 . The values of the site coefficients at short and 1 second period were plotted against the boreholes number as shown in figure 6. It was very evident that the amplification factor is highest at the region with the least average shear wave velocity of the top $30 \mathrm{~m}$ (Vs30) and thick overburden cover where borehole 4 is located, and least within the region where borehole 6 is located.

Hence region with low average shear wave velocity of the top $30 \mathrm{~m}(\mathrm{Vs} 30)$ and large overburden thickness will require some level of engineering remediation to increase its load bearing capacity and reduce the amplification of low frequency wave in the event of ground shaking due to seismic waves.

Table 3: Coordinate points and the determine Vs30 and Overburden Thickness at each borehole

\begin{tabular}{|r|r|r|r|r|}
\hline Borehole Point & Easting (Degree) & Northing (Degree) & Vs30 (m/s) & Overburden Thickness (m) \\
\hline BH1 & 5.593414 & 5.902992 & 830 & 9 \\
\hline BH2 & 5.593528 & 5.902294 & 772 & 10 \\
\hline BH3 & 5.593553 & 5.902186 & 976 & 6 \\
\hline BH4 & 5.592997 & 5.902894 & 634 & 11 \\
\hline BH5 & 5.593178 & 5.902603 & 759 & 8 \\
\hline BH6 & 5.592750 & 5.902272 & 1151 & 4 \\
\hline BH7 & 5.592411 & 5.902761 & 924 & 8 \\
\hline BH8 & 5.592533 & 5.902228 & 763 & 12 \\
\hline
\end{tabular}

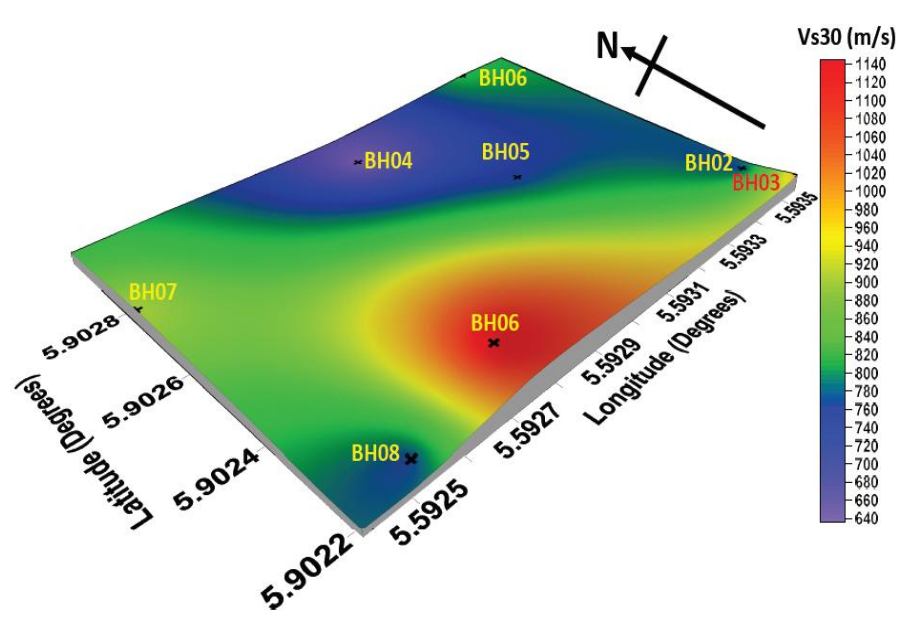

Figure 2: Site distribution of Vs30 within the survey area

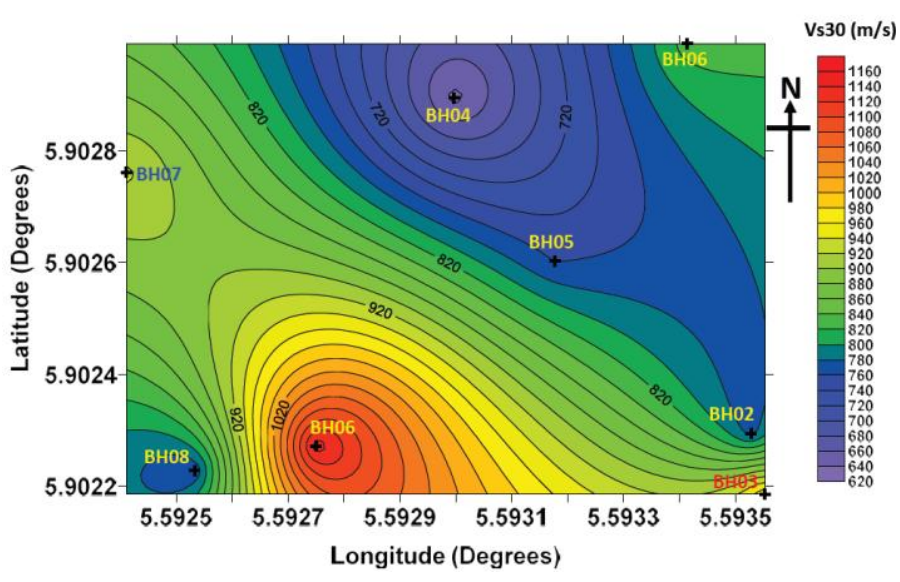

Figure 3: Equivalent contour map of site distribution of Vs30 within the survey area

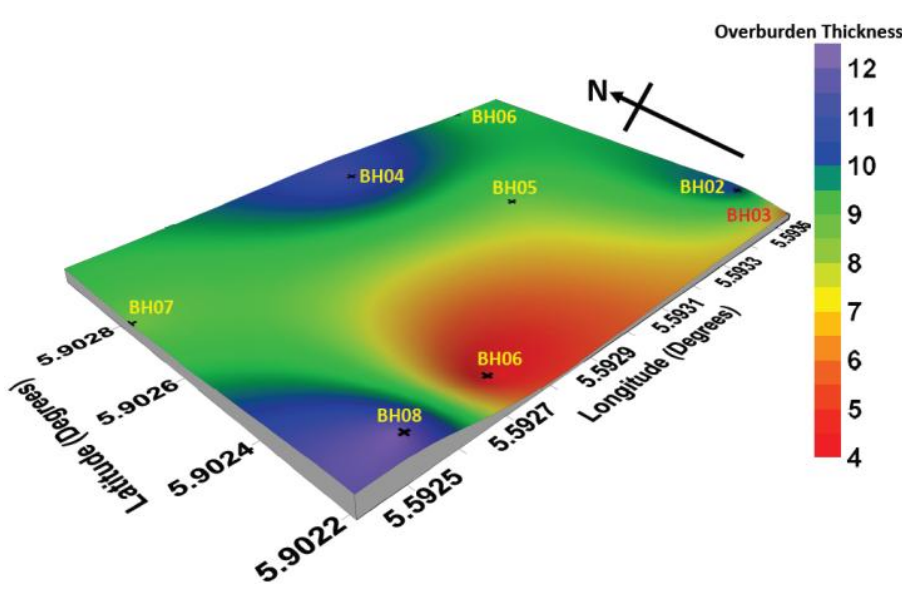

Figure 4: Site distribution of overburden within the survey area

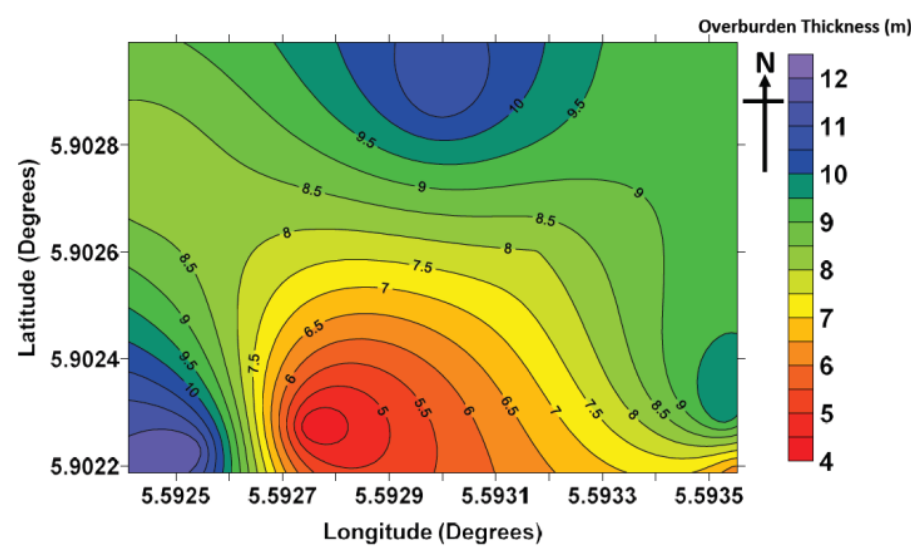

Figure 5: Equivalent contour map of site distribution of overburden within the survey area

Table 4: Fv and Fa Site Coefficient at short and 1 second period

\begin{tabular}{|l|r|r|r|r|}
\hline Boreholes & Easting (Degree) & Northing (Degree) & $\begin{array}{l}\text { Fa Site Coefficient } \\
\text { at short period }\end{array}$ & $\begin{array}{l}\text { lv Site Coefficient } \\
\text { at 1 second }\end{array}$ \\
\hline BH1 & 5.593414 & 5.902992 & 1.1 & 1.2 \\
\hline BH2 & 5.593528 & 5.902294 & 1.2 & 1.3 \\
\hline BH3 & 5.593553 & 5.902186 & 1 & 1.1 \\
\hline BH4 & 5.592997 & 5.902894 & 1.3 & 1.5 \\
\hline BH5 & 5.593178 & 5.902603 & 1.2 & 1.3 \\
\hline BH6 & 5.592750 & 5.902272 & 0.9 & 1 \\
\hline BH7 & 5.592411 & 5.902761 & 1.1 & 1.1 \\
\hline BH8 & 5.592533 & 5.902228 & 1.2 & 1.3 \\
\hline
\end{tabular}


ISSN (online): 2581-3048

IRJIET

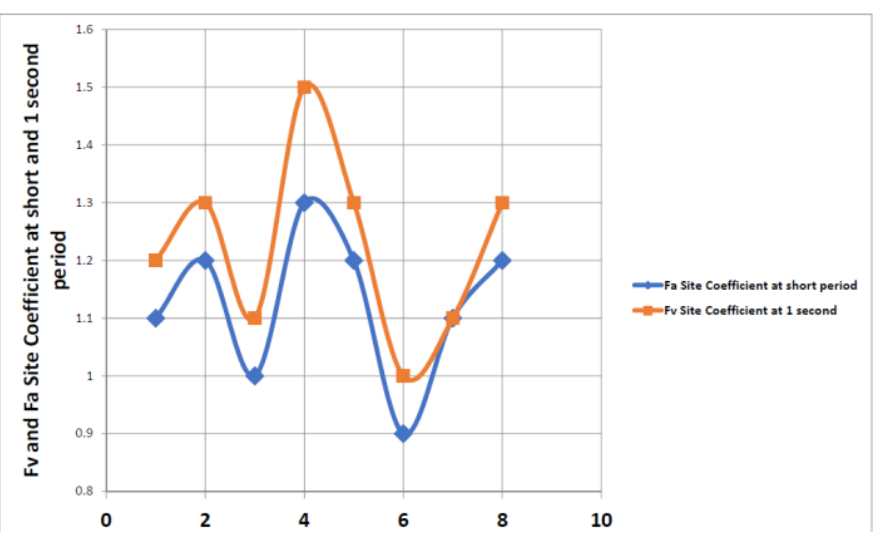

Figure 6: Plot of Fv and Fa Site Coefficient at short and 1 second period versus Borehole numbers

\section{CONCLUSION}

The research work has brought to the fore that the distribution of the average shear wave velocity of the top $30 \mathrm{~m}$ (Vs30) is not always even within a given site; rather we can have regions of low Vs30 and regions of high Vs30. It has also shown to a large extent that the overburden thickness correlate very well with the average shear wave velocity of the top $30 \mathrm{~m}$ (Vs30). The study has also revealed that in the event of a damaging earthquake, structures erected within the regions of low Vs30 characterize with thick overburden, will experience more amplification of the low frequency seismic waves that could eventually damage the structures, except if some level of engineering remediation is applied to increase the resistance to shaking and improve its load bearing capacity of the soil.

\section{REFERENCES}

[1] Ali I. K., P'eter, T., Zsolt, P., Ali, P., and L'aszl'o, H., (2006). Vs30 Mapping And Soil Classification For Seismic Site Effect Evaluation In Dinar Region, SW Turkey Geophys. J. Int. (2006) 165, 223-235, doi: 10.1111/j.1365-246X.2006.02882.xGJI.

[2] Collins C. C., (2018). Evaluation of layer Velocity Disparity and Lithological Changes within the
Volume 5, Issue 6, pp 1-4, June-2021

https://doi.org/10.47001/IRJIET/2021.506001

Subsurface Using High Resolution Downhole Seismic Method for Site Characterization. International Research Journal of Innovations in Engineering and Technology (IRJIET), Volume 2, Issue 9, pp 1-6, November-2018 ISSN (online): 2581-3048.

[3] Kogbe, C. A., (1989). The Cretaceous and Paleogene Sediments of Southern Nigeria. In: Geology of Nigeria, C.A. Kogbe, (editor), Elizabethan Press, Lagos: 311-334.

[4] Kyriazis, P., Evi, R., and Roula R., (2015). Site Characterization and Seismic Codes, Aristotle University of Thessaloniki, Greece Lab. of Soil Mechanics, Foundations and Geotechnical Earthquake Engineering 2015 ORFEUS Annual Observatory Coordination meeting Bucharest.

[5] Osakuni, M. U., and Abam, T. K., (2004). Shallow Resistivity Measurement for Cathodic Protection Of Pipelines In The Niger Delta. Environmental Geology. 45: 747-752.

[6] Short, K.C., and Stauble, A.J., (1967). Outline of the geology of the Niger Delta. Bull. AAPG. 51: 761779.

[7] Wright, J.B, Hasting, D. A., Jones, W. B., and Williams, H. R., (1985). Geology and mineral Resources of West Africa, Allen and Unwin Limited, $\mathrm{UK},: 107$.

\section{AUTHOR'S BIOGRAPHY}

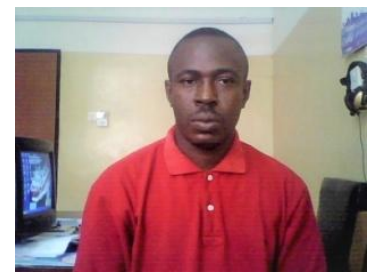

Dr Collins Chiemeke is an Associate Professor of Applied Geophysics, whose research interest is in the areas of: Seismology, 2D and 3D Seismic reflection, Seismic and Electrical Resistivity Tomography, MASW and Soil Thermal Resistivity.

\section{Citation of this Article:}

Collins C. Chiemeke, "Soil Categorization Using Vs30 Mapping, to Evaluate Probable Structural Effects of an Earthquake on a Proposed Construction Site" Published in International Research Journal of Innovations in Engineering and Technology IRJIET, Volume 5, Issue 6, pp 1-4, June 2021. Article DOI https://doi.org/10.47001/IRJIET/2021.506001 